Revue

Revue de l'histoire des religions

del'histoire des religions

$4 \mid 2009$

Varia

\title{
Jean-Michel LENIAUD [dir.], Le budget des cultes
}

Paris, École des chartes, 2007, 231 p., $30 \mathrm{~cm}, 25 €$ (« Matériaux pour

l'histoire » 5), $25 €$.

Séverine Blenner-Michel

(2) OpenEdition

Journals

Édition électronique

URL : http://journals.openedition.org/rhr/7311

DOI : $10.4000 /$ rhr.731

ISSN : 2105-2573

Éditeur

Armand Colin

Édition imprimée

Date de publication : 1 décembre 2009

Pagination : 666-669

ISBN : 978-2200-92592-5

ISSN : 0035-1423

\section{Référence électronique}

Séverine Blenner-Michel, « Jean-Michel LenIAud [dir.], Le budget des cultes », Revue de l'histoire des

religions [En ligne], 4 | 2009, mis en ligne le 15 mars 2011, consulté le 22 septembre 2020. URL : http:// journals.openedition.org/rhr/7311; DOI : https://doi.org/10.4000/rhr.7311

Ce document a été généré automatiquement le 22 septembre 2020.

Tous droits réservés 


\section{Jean-Michel LENIAUD [dir.], Le budget des cultes}

Paris, École des chartes, 2007, 231 p., $30 \mathrm{~cm}, 25 €$ (« Matériaux pour

l'histoire » 5), $25 €$.

\section{Séverine Blenner-Michel}

\section{RÉFÉRENCE}

Jean-Michel LENIAUd [dir.], Le budget des cultes, Paris, École des chartes, 2007, 231 p., 30 cm, $25 €$ (« Matériaux pour l'histoire » 5), $25 €$.

1 Cet ouvrage de grand format $(21 \times 29,7)$, préfacé par Jean-Marie Mayeur, se compose de deux parties distinctes. La première (p.9-105) est consacrée à la publication des actes d'une journée d'étude sur le budget des cultes qui s'est tenue le 30 janvier 2006; la seconde (p. 107-229) est une réédition scannée du précieux ouvrage éponyme de CharlesMarie Jourdain (1817-1886), qui fut publié en 1859 sous le titre Le budget des cultes en France, depuis le Concordat de 1801 jusqu'à nos jours (Paris, L. Hachette, II-327 p.). Philosophe de formation, orientaliste et académicien, Jourdain occupa, au cours de sa longue carrière administrative, les fonctions de chef de division de la comptabilité au Ministère de l'Instruction publique et des Cultes sous le Second Empire. De sa fréquentation quotidienne des chiffres et des budgets, il tira ce petit ouvrage qui, sur bien des points, complète ou remplace les archives du ministère des Cultes conservées dans la sous-série $\mathrm{F}$ ${ }^{19}$ des Archives nationales. Son utilité au sein de ce volume est une évidence.

2 Dans son introduction, Jean-Michel Leniaud rend hommage à l'initiative de Jean-Marie Mayeur et de Claude Langlois qui entreprirent, au début des années 1980, alors qu'ils enseignaient à l'Université de Paris XII - Val-de-Marne, une vaste enquête sur le budget des cultes à l'époque concordataire, dont l'objectif était de collecter des données brutes à partir des archives du ministère des Cultes (AN) et des tableaux de budget (BNF). Le matériau récolté demeura inexploité pendant plus d'un quart de siècle, jusqu'à ce que 
Claude Langlois lance l'idée d'organiser une journée d'étude consacrée au budget des cultes à l'occasion du centenaire de la loi de Séparation des Églises et de l'État. S'aidant des données collectées à l'époque, les intervenants de cette journée abordent la question budgétaire au travers de prismes aussi neufs que significatifs (les colonies, les cultes protestants et israélites, les dons et legs) ou revisitent des thèmes plus classiques (le culte catholique) sous l'angle des finances. Une contribution traite exclusivement de la question des sources archivistiques. Conservateur en chef à la section du XIX ${ }^{e}$ siècle des Archives nationales, en charge de la sous-série $\mathrm{F}^{19}$, Nadine Gastaldi y présente un vaste panorama des archives des cultes pour la période post-concordataire, de leur localisation dans les services d'archives publics et des instruments de recherche qui s'y rapportent. Elle attire ainsi l'attention de l'historien sur des fonds peu connus de l'après 1905, telle la documentation produite par le bureau central des Cultes - successeur à partir de $1911 \mathrm{du}$ feu ministère - et déposée à l'ancien Centre des Archives Contemporaines de Fontainebleau. Cette présentation, agrémentée de nombreuses captures d'écran, constitue un précieux guide à l'usage du chercheur en histoire religieuse qui s'interroge sur le devenir des cultes en France après 1905.

3 Les sept autres contributions adoptent une approche thématique et mettent en lumière trois aspects méconnus - ou du moins sous-estimés - du Concordat. Le premier concerne le traitement réservé aux cultes minoritaires. Les contributions d'André Encrevé et de Philippe Landau, consacrées respectivement aux cultes protestant et israélite invitent à balayer l'idée selon laquelle il y aurait eu une religion d'État à laquelle étaient réservés tous les subsides. On constate ainsi une augmentation nette des crédits dévolus aux Églises protestantes dès les monarchies constitutionnelles, qui se poursuit sans interruption jusqu'à l'inévitable inflexion, après 1881 , sous l'influence des républicains anticléricaux. Si l'on regarde de près, la régularité de cette augmentation contraste avec les restrictions apportées aux crédits du culte catholique sous certains régimes politiques. A. Encrevé note ainsi que «sous la Monarchie de Juillet l'État fait un effort important pour faciliter la vie des Églises protestantes» (p. 25), alors que, comme le montre C. Langlois, dans le même temps le régime de Louis-Philippe diminue les sommes allouées au culte catholique (p. 70). Si les montants consacrés au fonctionnement du culte israélite restent très inférieurs à ceux réservés aux cultes chrétiens, P. Landau en note lui aussi l'augmentation progressive à partir de la loi du 8 février 1831, qui dispose que les ministres $d u$ culte israélite recevront un traitement $d u$ Trésor public. Les trois confessions connaissent pourtant un sort commun à partir des années 1880 : bien que favorables aux républicains, protestants et juifs subissent les " dommages collatéraux " de la politique anticléricale qui vise d'abord les catholiques.

L'ouverture sur les colonies constitue le deuxième point fort de ce livre. Philippe Delisle distingue les vieilles colonies (Antilles, Réunion), où sont créés trois diocèses en 1850, de l'Algérie et du reste de l'empire colonial. Il note que les dépenses du culte dans les territoires autres que l'Algérie concernent presque exclusivement le catholicisme. En Algérie, en revanche, le culte musulman, largement majoritaire, est lui aussi rétribué par l'État et représente le deuxième poste budgétaire derrière la religion catholique. Le cas de l'Algérie se distingue également par l'évolution des crédits: le budget des cultes y demeure relativement stable à la fin du siècle et continue d'exister après l'entrée en vigueur de la loi de Séparation, l'administration craignant de détourner, par une application trop stricte de sa politique anticléricale, les catholiques algériens vers des puissances étrangères. 
Les contributions de Claude Langlois, Jean-Michel Leniaud, Jean-Luc Marais et Jean-Pierre Moisset permettent enfin d'aborder la question, rarement traitée jusque-là, de la place du budget des cultes dans le financement des cultes reconnus et de la diversité des financements, aussi bien publics que privés. Dans le cas du catholicisme parisien au XIX siècle, J.-P. Moisset souligne la place prépondérante des contributions communales par rapport au budget des cultes et l'apport indispensable des financements privés dans la rétribution du clergé. C. Langlois parle de "privatisation progressive des dépenses " (p. 71) et fait remarquer que l'augmentation constante de la générosité privée - dont les dons et legs constituent un exemple - va de pair avec le lent recul de la part des cultes dans le budget global de l'État. Sur ce point, J.-M. Leniaud invite à la prudence, rappelant à juste titre que le budget des cultes doit être compris dans un sens large et qu'il ne faut pas oublier de porter au rang des dépenses cultuelles celles qu'engendrent les diverses aumôneries (militaires, des lycées, des hôpitaux, des asiles d'aliénés) et la décoration des églises, prises en charge par d'autres ministères que celui des Cultes.

6 Nul doute que cet ouvrage rendra de grands services aux historiens des XIX et $\mathrm{XX}^{\mathrm{e}}$ siècles, spécialistes de l'histoire administrative, politique et/ou religieuse de la France. Les contributions qui éclairent judicieusement, au travers d'une approche financière, la complexité et l'originalité du système concordataire, contribuent à faire connaître des sources jusque-là mal connues, du moins rarement utilisées. Il est à regretter, de ce point de vue, que l'origine des chiffres mentionnés dans les différentes contributions ne soit pas toujours très clairement notifiée. On ne trouve ainsi pas systématiquement les cotes ou les références exactes des archives d'où sont tirées les données statistiques. Si elle ne nuit en aucune manière à la compréhension des textes, cette lacune interdit à quiconque les lira de revenir à la source de l'information. Mais sans doute l'objectif de ce volume estil précisément d'épargner cette peine à de futurs chercheurs en éditant des données difficilement repérables dans la masse des archives ministérielles. L'intérêt porté par les organisateurs de cette journée aux sources elles-mêmes, souligné par la réédition en appendice de l'introuvable ouvrage de Charles Jourdain, plaident en faveur de cette hypothèse. Le choix de la collection de l'École des chartes "Matériaux pour l'Histoire » prend de ce fait tout son sens.

7 On relèvera, avant de conclure, l'évidente dissymétrie dans le traitement des périodes concordataire et post-concordataire. Cette distinction, qui ne surprend pas étant donné le sujet traité, est néanmoins assez significative de la rupture brutale que constitue encore aujourd'hui pour l'historiographie religieuse la loi de Séparation. Seule l'intervention de J.-L. Marais sur les dons et legs à l'Église catholique prolonge - et encore de manière succincte - l'étude jusqu'aux années 1950 avec l'analyse du devenir de ces libéralités après 1905. Face au vide bibliographique que constitue la question du financement des cultes reconnus et de leurs rapports avec l'État laïc au $\mathrm{xx}^{\mathrm{e}}$ siècle, l'intervention de $\mathrm{N}$. Gastaldi sonne comme une invitation à défricher plus largement cette terre encore vierge à partir de sources qui s'annoncent prometteuses. Il n'y a plus qu'à espérer que son appel sera entendu. 


\section{AUTEURS}

SÉVERINE BLENNER-MICHEL

Université de Picardie. 